\section{Dietary Menhaden Oil Lowers Plasma Prostaglandins and Calcium in Mice Bearing the Prostaglandin-Producing HSDM $_{1}$ Fibrosarcoma}

\author{
Armen H. Tashjian, Jr., Edward F. Voelkel, \\ Dwight R. Robinson, and Lawrence Levine \\ Laboratory of Toxicology, Harvard School of Public Health, and \\ Department of Pharmacology, Harvard Medical School, Boston, \\ Massachusetts 02115; Arthritis Unit, Massachusetts General \\ Hospital, Boston, Massachusetts 02114; and Graduate \\ Department of Biochemistry, Brandeis University, \\ Waltham, Massachusetts 02254
}

bstract. The $\omega 3$ class of polyunsaturated fatty acids, particularly eicosapentaenoic acid (EPA, 20:5), has been shown to alter the patterns of arachidonic acid (20:4) metabolism in both in vitro and in vivo systems. To examine further the role of arachidonic acid conversion to prostaglandins (PG) in hypercalcemic mice bearing the PG-producing $\mathrm{HSDM}_{1}$ fibrosarcoma, we have performed experiments in which control and tumor-bearing animals were fed diets either low (0.1$0.2 \%$ of total fatty acid) or high (17\%) in EPA. In all five experiments performed, tumor-bearing mice eating control diets had markedly elevated (average sixfold above control) plasma concentrations of 13,14-dihydro15-keto-PGE 2 ( $\left.\mathrm{PGE}_{2}-\mathrm{M}\right)$, while in mice bearing $\mathrm{HSDM}_{1}$ tumors and eating the EPA-enriched menhaden oil diet, the elevation was reduced to only twice control values. The increase in plasma calcium concentration $(\sim 2.5$ $\mathrm{mg} / \mathrm{dl}$ above control) in tumor-bearing animals was also reduced significantly $(P<0.05)$ to only $1.3 \mathrm{mg} / \mathrm{dl}$ above control in mice eating the diet enriched in EPA. Plasma immunoreactive hydroxy fatty acids (i12-HETE) and sulfidopeptide leukotrienes (iSRS) were not elevated in tumor-bearing mice and were unaffected by diet. The

Dr. Levine is an American Cancer Society Professor of Biochemistry (Award PRP-21).

Address reprint requests to Dr. Tashjian, Jr., Harvard School of Public Health.

Received for publication 11 April 1984 and in revised form 30 July 1984.

J. Clin. Invest.

(c) The American Society for Clinical Investigation, Inc. 0021-9738/84/12/2042/07 \$1.00

Volume 74, December 1984, 2042-2048 contents of $\mathrm{PGE}_{2}, \mathrm{PGF}_{2 \alpha}$, and 6-keto-PGF $\mathrm{PG}_{1 \alpha}$ were lower in tumor tissue from animals eating the diet high in EPA, whereas the tissue contents of i12-HETE and iSRS were not altered by diet. Fatty acid analysis of liver and tumor tissue revealed marked increases in certain $\omega 3$ fatty acids (20:5, 22:5, and 22:6) from animals eating the enriched diet. Body weights, tumor weights, and tumor histology were not significantly altered by diet. To determine whether dietary calcium played a role in the elevation of plasma calcium in mice bearing the $\mathrm{HSDM}_{1}$ tumor and the reduction of plasma calcium in animals fed EPA, we compared results in mice fed diets containing $0.80 \%$ (normal) and $0.015 \%$ (deficient) calcium. The increases in plasma calcium and $\mathrm{PGE}_{2}-\mathrm{M}$ observed in tumor-bearing mice were the same on both normal and very low calcium intakes. We conclude, in mice of the Swiss albino strain bearing the HSDM fibrosarcoma, that consumption of a diet enriched in EPA reduces the production of cyclooxygenase products of arachidonic acid metabolism and thereby reduces the elevation of plasma calcium concentration. Dietary enrichment with EPA did not alter the production of serologically determined lipoxygenase products of arachidonic acid.

\section{Introduction}

We have described an animal model in which a prostaglandin (PG)'-producing fibrosarcoma $\left(\mathrm{HSDM}_{1}\right)$ is associated with

1. Abbreviations used in this paper: EPA, 5,8,11,14,17-eicosapentaenoic acid or 20:5; i12-HETE, immunoreactive 12-hydroxy-eicosatetraenoic acid; iSRS, immunoreactive 6-sulfidopeptide-containing leukotrienes; $\mathrm{PG}$, prostaglandin(s); $\mathrm{PGE}_{2}, \mathrm{PGF}_{2 \alpha}$, and $\mathrm{PGI}_{2}$, prostaglandin $\mathrm{E}_{2}, \mathrm{~F}_{2 \alpha}$, and $I_{2}$, respectively; $P G E_{2}-M, 13,14-$ dihydro-15-keto-PGE ${ }_{2}$. 
elevated plasma calcium in mice bearing this tumor (1-3). Pharmacological inhibition of PG synthesis in tumor-bearing animals by administration of cyclooxygenase inhibitors or hydrocortisone is associated with parallel decreases in the concentrations of plasma $\mathrm{PGE}_{2}$ metabolites and calcium (4$6)$. These results, and the findings from a variety of in vitro studies with HSDM 1 cells and bone in culture (7-11), have led us to conclude that the hypercalcemic syndrome in mice bearing the $\mathrm{HSDM}_{1}$ tumor is caused by the high rate of production of $\mathrm{PGE}_{2}$ by tumor cells and the subsequent bone resorption-stimulating action of this PG on the skeleton.

It is possible to alter arachidonic acid metabolism and PG synthesis in vitro $(12,13)$, in animals $(14-16)$ and in people $(17,18)$, by alterations in the composition of nutrient polyunsaturated fatty acids, especially 5,8,11,14,17-eicosapentaenoic acid or 20:5 (EPA). Particularly intriguing have been the results of studies relating high EPA intake to a lowered incidence of cardiovascular deaths (19). The mechanisms of action of dietary EPA are not entirely clear, although several sorts of results lead to plausible hypotheses. These include a decrease in arachidonic acid content in precursor pools for the synthesis of the 2-series of PGs, prostacyclins, and thromboxanes; an increase in EPA in precursor pools leading to the formation of 3-series cyclooxygenase products; and direct or indirect inhibition of arachidonic acid metabolism (20, 21). These findings suggested to us that, in mice bearing the $\mathrm{HSDM}_{1}$ tumor, consumption of a diet enriched in EPA might lead to inhibition of $\mathrm{PGE}_{2}$ overproduction and to reduction of the elevated plasma calcium concentration. In addition, because no previous data have been reported on the possible involvement of lipoxygenase products of arachidonic acid metabolism in mice bearing the HSDM $\mathrm{H}_{1}$ tumor, we measured these products serologically.

Our findings reveal that mice fed a menhaden oil-supplemented diet containing $\sim 17 \%$ EPA (control diets contained 0.1-0.2\% EPA) for 5-6 wk had marked enrichment of their tissue contents of $\omega 3$ fatty acids. In mice bearing the $\mathrm{HSDM}_{1}$ tumor, the sixfold increase in plasma 13,14-dihydro-15-keto$\mathrm{PGE}_{2}\left(\mathrm{PGE}_{2}-\mathrm{M}\right)$ was reduced to only twice the control value, and the average increase in plasma calcium in tumor-bearing mice of $2.5 \mathrm{mg} / \mathrm{dl}$ in animals on control diets was decreased to only $1.3 \mathrm{mg} / \mathrm{dl}$ above control in mice eating the menhaden oil diet. No statistically significant changes were noted in plasma lipoxygenase products (immunoreactive 12-hydroxyeicosatetraenoic acid [i12-HETE] or immunoreactive 6-sulfidopeptide-containing leukotrienes [iSRS]) in control or tumorbearing animals eating control or fish oil-supplemented diets. Changes in the contents of cyclooxygenase and lipoxygenase products of arachidonic acid metabolism in tumor tissue paralleled those observed in plasma. Hypercalcemia in tumorbearing mice was independent of dietary calcium intake.

\section{Methods}

Animals. The HSDM, fibrosarcoma was passed serially in male mice of the Swiss albino strain by methods described previously (1). In brief, healthy tumor tissue from a donor mouse was minced into small fragments, passed through a tissue press, and the fine particles suspended in Gey's balanced salt solution at a ratio of $5 \mathrm{ml} / \mathrm{g}$ wet weight of tumor. About $0.25 \mathrm{ml}$ of this suspension was injected subcutaneously in the back of the neck of each recipient animal.

In all the experiments described in this report mice were randomly divided into three dietary treatment groups at the beginning of each experiment. The groups were fed regular mouse chow, a beef tallow diet, or a menhaden oil diet (see below). Each group of mice ate the appropriate diet for $2.5 \mathrm{wk}$ before the injection of tumor cells. In preliminary experiments, we found that the plasma concentrations of cyclooxygenase products of arachidonic acid metabolism were reduced maximally in mice of this strain within $2.5 \mathrm{wk}$ of starting to eat the menhaden oil diet. The experiment was then continued for an additional 3-3.5 wk and was terminated by killing the mice with an overdose of ether anesthesia. Blood and tissues were obtained for analyses as described below.

Diets. The regular mouse chow diet was Purina 5015 (Ralston Purina Co., St. Louis, MO) and is referred to hereafter as "regular" diet. The experimental beef and fish diets were prepared as follows. The basic diet consisted of a fat-free powder (ICN Nutritional Biochemicals, Cleveland, $\mathrm{OH}$ ) which contained by weight $21 \%$ casein, $15.6 \%$ cellulose, $58.5 \%$ sucrose, and $4 \%$ balanced salt mixture, plus essential vitamins. This was mixed three parts to one by weight with either melted beef tallow (ICN Nutritional Biochemicals) or refined whole menhaden oil (Zapata Haynie Corp., Reedville, VA), a rich source of $\omega 3$ fatty acids, to give the "beef tallow" or "menhaden oil" diets, respectively, each containing $25 \mathrm{wt} \%$ fat. The fatty acid compositions of the diets are given in Results.

In two experiments with control and tumor-bearing animals, the effects on plasma concentrations of calcium and $\mathrm{PGE}_{2}-\mathrm{M}$ were compared in mice receiving diets of normal and very low calcium content. The normal calcium-containing diet was regular mouse chow Purina 5015 (Ralston Purina Co.) (calcium content $0.80 \%$ ), and the calciumdeficient diet (calcium content $0.015 \%$ ) was that described by Kenny and Munson (22). For these experiments, the mice were given the normal or calcium-deficient diets on the day of tumor implantation, and the experiments continued for $3 \mathrm{wk}$ as described above.

Tissues. At the termination of each experiment, the animals were weighed, and the tumors were carefully excised, weighed, and extracted in Gey's balanced salt solution $(5 \mathrm{ml} / \mathrm{g})$ containing indomethacin (10 $\mu \mathrm{g} / \mathrm{ml}$ ). After homogenization for $30 \mathrm{~s}$ at $4^{\circ} \mathrm{C}$ in a Waring blender, the crude extract was centrifuged for $30 \mathrm{~min}$ at $10,000 \mathrm{~g}$ and the supernatant solution was used for assay of arachidonic acid metabolites (see below). Tumor and liver were also processed for analysis of fatty acid contents as described below.

Histology. Tumor tissue from animals on the regular, beef and fish diets was preserved in $10 \%$ formalin solutions, and then processed and stained with hematoxylin and eosin. Sections from five or six separate tumors from each of the three treatment groups were examined without knowledge of the dietary history of the donor animals.

Fatty acid analysis. Diets, tumor tissue or liver, were extracted using an ethanol/ether procedure (23). Methyl esters of the extracted samples were prepared using a $16-\mathrm{h}$ incubation at $65^{\circ} \mathrm{C}$ with $0.5 \mathrm{~N}$ methanolic HCl. Samples were evaporated, washed with methanol, taken to dryness, and resuspended in chloroform. Aliquots were injected into a $1 / 8^{\prime \prime} \times 5^{\prime}$ stainless steel column packed with $10 \%$ Silar $10 \mathrm{C}$ on Gas Chrom Q 100/200 mesh using a Perkin Elmer 900 gas chromatograph (Perkin-Elmer Corp., Norwalk, CT). The instrument was programmed to begin at $150^{\circ} \mathrm{C}$ and rise $4^{\circ} \mathrm{C} / \mathrm{min}$ to $255^{\circ} \mathrm{C}$.

Measurement of plasma calcium. Individual anesthetized mice were 
bled either by cardiac puncture into heparinized syringes or by orbital sinus puncture into heparinized Pasteur pipettes. Blood was kept on ice and centrifuged at $4^{\circ} \mathrm{C}$ within $30 \mathrm{~min}$, and the plasma separated for measurements of calcium and arachidonic acid metabolites. Calcium was measured with a Corning calcium analyzer (Corning Medical Instruments, Medfield, MA), model 940, by fluorometric titration.

Measurement of arachidonic acid metabolites. Essentially the same serologic methods were used for plasma and tumor extracts. The concentration of each compound was determined by radioimmunoassay using antisera of known specificities. The antibodies directed against $\mathrm{PGE}_{2}$ and $\mathrm{PGF}_{2 \alpha}$ are highly specific (24). The anti-PGE $-\mathrm{M}$ crossreacts $5 \%$ with $\mathrm{PGF}_{2 \alpha}-\mathrm{M}$ (25). The anti-PGF ${ }_{2 \alpha}-\mathrm{M}$ crossreacts $3 \%$ with $\mathrm{PGE}_{2}-\mathrm{M}$ (25). 6-keto-PGF $\mathrm{PG}_{1 \alpha}$ was measured as described previously (25, 26). The antibodies raised against 12-HETE and iSRS are only classspecific. In addition to the homologous 12-HETE, this class-specific antibody crossreacts $20 \%$ with leukotriene $B_{4}$ and 2-5\% with 5-HETE and 15-HETE (27). Measurements with this immune system are, therefore, expressed as i12-HETE (immunoreactive 12-HETE). The anti-leukotriene serum reacts with leukotrienes $C_{4}, D_{4}, E_{4}$, and their 11-trans-stereoisomers with similar affinities (28). Measurements with this immune system are, therefore, expressed as iSRS.

Statistical analysis. Results of each experiment (numbers of mice or samples per group are given in the appropriate figure or table legends) were subjected to analysis of variance, and the standard errors were calculated from the residual error term of that analysis. Where appropriate and when variances were not heterogeneous, data were pooled from experiments of similar design.

\section{Results}

Fatty acid composition of diets. Fatty acid analysis of the lipids in the three diets are given in Table I. The compositions of the regular chow diet and the beef tallow diet were similar,

Table I. Fatty Acid Composition of the Three Diets Used

\begin{tabular}{lcrr}
\hline & \multicolumn{3}{l}{ Fatty acid content (\% total) } \\
\cline { 2 - 4 } Fatty acid & \multicolumn{1}{c}{ Regular } & Beef & \multicolumn{1}{c}{ Fish } \\
\hline $14: 0$ & 2.0 & 4.0 & 13.0 \\
$16: 0$ & 19.0 & 23.0 & 13.0 \\
$16: 1$ & 4.0 & 6.0 & 16.0 \\
$18: 0$ & 7.5 & 11.0 & 4.0 \\
$18: 1$ & 33.0 & 45.0 & 11.0 \\
$18: 2$ & 24.0 & 6.0 & 5.0 \\
$18: 3$ & $<0.1$ & 0.6 & $<0.1$ \\
$20: 3$ & $<0.1$ & $<0.1$ & 0.2 \\
$20: 4$ & 0.5 & $<0.1$ & 1.0 \\
$20: 5$ (EPA) & 0.2 & 0.1 & 17.0 \\
$22: 4$ & $<0.1$ & $<0.1$ & $<0.1$ \\
$22: 5$ & $<0.1$ & $<0.1$ & 2.0 \\
$22: 6$ & $<0.1$ & $<0.1$ & 7.0 \\
& & &
\end{tabular}

Using this analytic method, quantitative results of replicate determinations agree within $\pm 14 \%$.
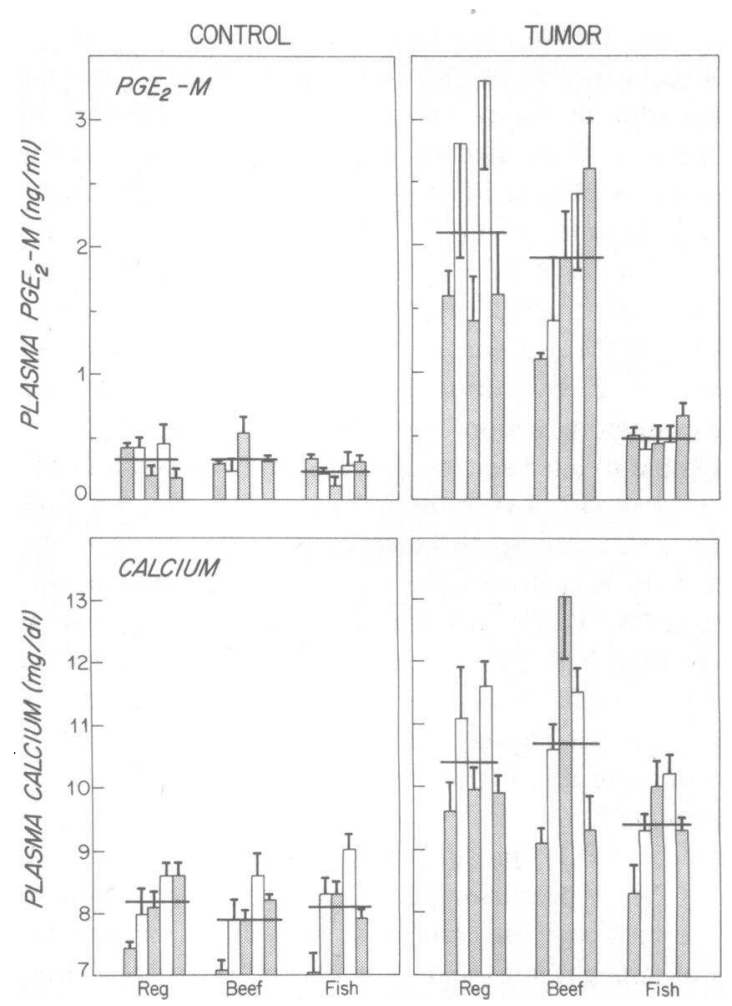

Figure 1. Plasma concentrations of $\mathrm{PGE}_{2}-\mathrm{M}$ and calcium in control and tumor-bearing mice fed a regular chow diet (Reg), a beef tallow diet (Beef), or a menhaden oil diet (Fish). The results of five separate experiments are shown. For each diet, the individual bars give the mean values and the brackets give the SE for groups of 5-10 mice in each experiment. The strong horizontal line across all five bars gives the overall average for the five experiments. In control mice on the beef tallow diet, only four experiments were assayed for plasma $\mathrm{PGE}_{2}-\mathrm{M}$ (upper left panel).

except for a higher content of linoleic acid (18:2) in the regular diet. The most important differences are the high contents of long chain polyunsaturated $\omega 3$ fatty acids, 20:5 (EPA), 22:5, and 22:6, in the menhaden oil diet, whereas the contents of these fatty acids are negligible in the other diets.

Menhaden oil diet and plasma concentrations of arachidonic acid metabolites and calcium. The individual results of five sequential, independent experiments are presented in Fig. 1. In mice eating the regular chow and beef tallow diets, plasma $\mathrm{PGE}_{2}-\mathrm{M}$ concentrations were increased on average 6.4- and 5.9-fold, respectively, above control $(P<0.001)$ in tumorbearing animals, while in tumor-bearing mice eating the menhaden oil diet the increase was only 2.2 -fold above the value in menhaden oil control animals $(P<0.05)$. In absolute terms, the average plasma $P G_{2}-M$ concentrations in tumor-bearing animals eating the regular and beef tallow diets were 1.77 and $1.58 \mathrm{ng} / \mathrm{ml}$ above control, respectively, whereas the average value for animals eating the menhaden oil diet was only 0.26 $\mathrm{ng} / \mathrm{ml}$ above control. 
In mice eating the chow and beef tallow diets, plasma calcium concentrations were increased 2.2 and $2.8 \mathrm{mg} / \mathrm{dl}$, respectively, above control $(P<0.01)$ in tumor-bearing animals, whereas in mice eating the menhaden oil diet, the increase in calcium was only $1.3 \mathrm{mg} / \mathrm{dl}$ above control $(P<0.05)$. In mice bearing the $\mathrm{HSDM}_{1}$ tumor, the average plasma calcium concentration $(9.4 \mathrm{mg} / \mathrm{dl})$ was significantly lower $(P<0.05)$ than the average values for mice eating the regular chow $(10.4 \mathrm{mg} /$ dl) or beef tallow $(10.7 \mathrm{mg} / \mathrm{dl})$ diets. Thus, the fish oilsupplemented diet reduced markedly the elevated plasma concentrations of $\mathrm{PGE}_{2}-\mathrm{M}$ in tumor-bearing mice, and also the plasma calcium concentration. However, neither the $\mathrm{PGE}_{2}-\mathrm{M}$ nor calcium concentrations returned to the levels observed in control nontumor-bearing mice.

Plasma concentrations of i12-HETE were not elevated in mice bearing the $\mathrm{HSDM}_{1}$ tumor on any of the three diets. Mean values for control and tumor-bearing regular, beef, and menhaden oil diets were, respectively, 11.5 vs. $13.5 \mu \mathrm{g} / \mathrm{ml}$, 11.8 vs. $11.1 \mu \mathrm{g} / \mathrm{ml}$, and 6.6 vs. $7.0 \mu \mathrm{g} / \mathrm{ml}$. Values for i12HETE, although numerically lower in animals eating the menhaden oil diet, were not statistically different $(P>0.05)$ from those on regular or beef tallow diets.

Plasma concentrations of iSRS were unchanged under all experimental circumstances. Mean values for control and tumor-bearing mice eating regular, beef, and menhaden oil diets were, respectively, 16 vs. $15 \mathrm{ng} / \mathrm{ml}, 16$ vs. $15 \mathrm{ng} / \mathrm{ml}$, and 15 vs. $15 \mathrm{ng} / \mathrm{ml}$. It should be recognized that the i12-HETE and iSRS data, having been obtained with class-specific antisera (27), could obscure changes in individual serologically active species of HETE or SRS. Only immunochromatographic analyses can identify the immunologically active lipoxygenase products. Such analyses, in order to yield statistically reliable data, are not feasible at this time.

Tumor contents of arachidonic acid metabolites and tissue fatty acid composition. The contents of $\mathrm{PGE}_{2}, \mathrm{PGF}_{2 \alpha}$, 6-ketoPGF $_{1 \alpha}$, i12-HETE, and iSRS were measured in extracts of tumor tissue (Fig. 2). The values for all arachidonate metabolites determined were not different for animals eating the regular chow or beef tallow diets. However, the contents of $\mathrm{PGE}_{2}$, $\mathrm{PGF}_{2 \alpha}$, and 6-keto-PGF PG $_{1 \alpha}$ were lower in tumors from animals eating the menhaden oil diet. The tissue concentrations of i12HETE and iSRS did not differ significantly among the three diets. Qualitatively similar results were obtained in a second experiment (data not shown).

The fatty acid composition of liver and tumor tissue were determined in three experiments for tumor-bearing animals on the three different diets (Table II). The most striking findings were the marked increases in certain $\omega 3$ fatty acids (20:5, 22:5, and 22:6) in both tissues from animals eating the menhaden oil diet. No major differences were noted between liver and tumor tissue or between the regular and beef tallow diets. Thus, the fish diet modified quantitatively not only the plasma metabolites of arachidonic acid but also the fatty acid composition of tissues.

Body weight and tumor weight. Body weight was increased $\sim 6 \mathrm{~g}(P<0.05)$ in tumor-bearing animals on all three diets. The increment is explained largely by the mass of the tumor $(6-10 \mathrm{~g})$. The average values for body weight $(37 \mathrm{~g})$ or tumor weight $(7.2 \mathrm{~g})$ were not significantly $(P>0.05)$ lower in animals eating the menhaden oil diet than in animals eating control (40 and $8.9 \mathrm{~g}$, respectively) or beef (40 and $9.0 \mathrm{~g}$, respectively) diets. Therefore, the lower values for calcium and arachidonic acid metabolites in plasma (Fig. 1) in mice eating the fish diet cannot be explained merely by a decrease in the size of the tumors in these animals.

Histology. Careful microscopic examination of histological sections of tumor tissue taken from animals fed each of the three diets revealed no observable differences between the groups. In particular, there was no evidence of extensive necrosis, and the moderate inflammatory reaction surrounding the tumor was similar in all three dietary groups.

Calcium-deficient diet and plasma concentrations of $P G E_{2}-M$ and calcium. It has been reported that the PGproducing $\mathrm{VX}_{2}$ carcinoma in the rabbit induces hypercalcemia by a mechanism that requires substantial amounts of calcium in the diet (29). Therefore, it could be argued by analogy that
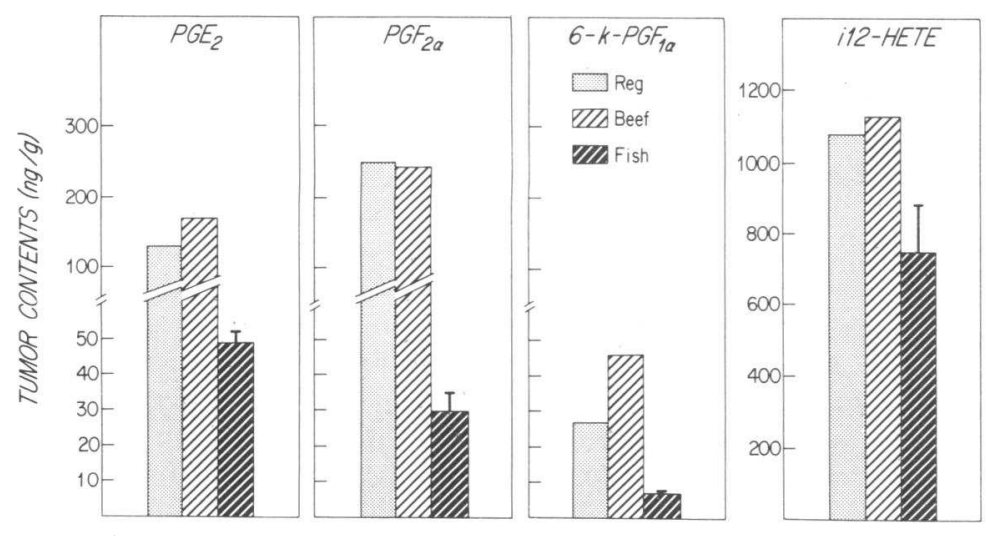

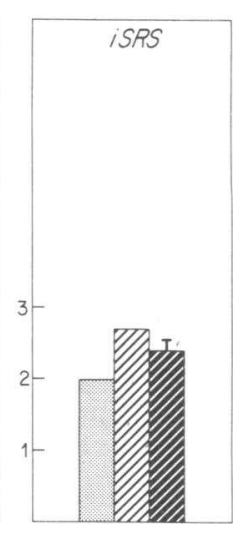

Figure 2. Concentrations of metabolites of arachidonic acid in extracts of tumors removed at $3 \mathrm{wk}$ from animals eating a regular chow diet (Reg), a beef tallow diet (Beef), or a menhaden oil diet (Fish). Each bar gives the value (assayed in duplicate) for an extract of a pool of 4-7 tumors for the regular and beef diet groups. The bars for the fish diet groups give the mean values of two separate pools of 4-8 tumors, and the brackets give the ranges. Qualitatively, similar results were obtained in a second independent experiment. Note the scales on the ordinates for i12-HETE and iSRS are different from those for $\mathrm{PGE}_{2}, \mathrm{PGF}_{2 \alpha}$, and 6-keto$\mathrm{PGF}_{1 \alpha}$. 
Table II. Fatty Acid Composition of Liver and Tumor Tissue from Mice on Regular

Chow Diet, Beef Tallow Diet, and Menhaden Oil Diet

\begin{tabular}{|c|c|c|c|c|c|c|}
\hline \multirow[b]{3}{*}{ Fatty acid } & \multicolumn{6}{|c|}{ Fatty acid content (\% total) } \\
\hline & \multicolumn{2}{|l|}{ Regular } & \multicolumn{2}{|l|}{ Beef } & \multicolumn{2}{|l|}{ Fish } \\
\hline & Liver & Tumor & Liver & Tumor & Liver & Tumor \\
\hline $14: 0$ & $0.3 \pm 0.05$ & $1.0 \pm 0.10$ & $0.3 \pm 0.05$ & $1.0 \pm 0.10$ & $0.6 \pm 0.20$ & $2.9 \pm 0.69$ \\
\hline $16: 0$ & $22.0 \pm 0.5$ & $18.0 \pm 0.47$ & $20.0 \pm 0.0$ & $16.0 \pm 2.2$ & $27.0 \pm 0.0$ & $22.0 \pm 2.5$ \\
\hline $16: 1$ & $1.8 \pm 0.2$ & $4.5 \pm 0.33$ & $2.6 \pm 0.4$ & $6.8 \pm 1.6$ & $3.4 \pm 0.5$ & $8.4 \pm 0.60$ \\
\hline 18:0 & $14.0 \pm 2.5$ & $14.0 \pm 0.47$ & $16.0 \pm 2.0$ & $12.0 \pm 2.5$ & $18.0 \pm 2.5$ & $15.0 \pm 3.1$ \\
\hline 18:1 & $21.0 \pm 3.0$ & $28.0 \pm 1.7$ & $32.0 \pm 1.0$ & $45.0 \pm 5.2$ & $15.0 \pm 1.5$ & $25.0 \pm 0.83$ \\
\hline $18: 2$ & $18.0 \pm 3.5$ & $16.0 \pm 1.2$ & $7.0 \pm 1.0$ & $6.1 \pm 0.1$ & $4.5 \pm 0.5$ & $4.2 \pm 1.2$ \\
\hline $18: 3$ & $0.8 \pm 0.2$ & $1.0 \pm 0.10$ & $0.5 \pm 0.1$ & $1.1 \pm 0.17$ & $0.5 \pm 0.0$ & $1.0 \pm 0.05$ \\
\hline $20: 3$ & $1.2 \pm 0.2$ & $1.8 \pm 0.24$ & $1.8 \pm 0.20$ & $0.8 \pm 0.58$ & $0.6 \pm 0.1$ & $0.3 \pm 0.1$ \\
\hline $20: 4$ & $10.0 \pm 2.0$ & $6.7 \pm 0.47$ & $10.0 \pm 1.0$ & $3.6 \pm 2.2$ & $6.0 \pm 1.0$ & $2.7 \pm 0.55$ \\
\hline $20: 5$ & $0.1 \pm 0.0$ & $0.3 \pm 0.17$ & $0.3 \pm 0.20$ & $0.6 \pm 0.20$ & $6.3 \pm 0.7$ & $5.6 \pm 2.0$ \\
\hline $22: 4$ & $0.2 \pm 0.15$ & $0.6 \pm 0.37$ & $0.2 \pm 0.05$ & $0.3 \pm 0.23$ & $<0.1$ & $<0.1$ \\
\hline $22: 5$ & $0.3 \pm 0.10$ & $0.7 \pm 0.25$ & $0.7 \pm 0.60$ & $0.2 \pm 0.08$ & $2.0 \pm 0.10$ & $3.6 \pm 0.92$ \\
\hline $22: 6$ & $7.5 \pm 0.50$ & $3.4 \pm 1.2$ & $4.2 \pm 0.80$ & $1.5 \pm 1.3$ & $17.0 \pm 1.0$ & $5.0 \pm 2.0$ \\
\hline
\end{tabular}

Values for liver are the mean of two experiments \pm range. Values for tumor tissue are the mean of three experiments \pm SE.

the reduction in plasma calcium, which we observed in mice eating a diet enriched in EPA, might be the result of decreased absorption of dietary calcium mediated either by cyclooxygenase products of arachidonic acid metabolism or by other means. The data in Fig. 3 show, in two separate experiments, that the elevation of plasma calcium $(P<0.01)$ regularly observed in animals bearing the $\mathrm{HSDM}_{1}$ tumor while eating a chow diet $(0.80 \%$ calcium $)$ is observed to the same extent in mice eating a diet very low in calcium content $(0.015 \%$ calcium). The increase in plasma $\mathrm{PGE}_{2}-\mathrm{M}$ was also the same in tumor-

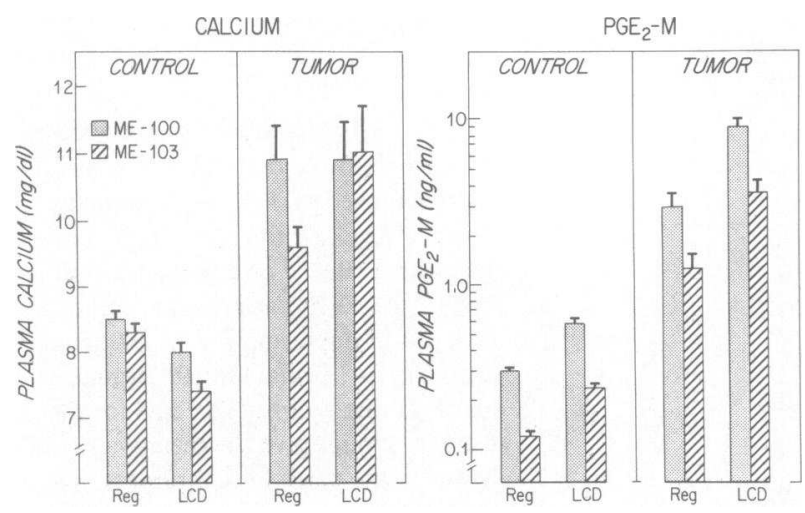

Figure 3. Concentrations of calcium and $\mathrm{PGE}_{2}-\mathrm{M}$ in control and tumor-bearing mice eating a chow diet (Reg) or a low calcium diet (LCD). The results of two independent experiments (exps. ME-100 and ME-103) are shown. Each bar gives the mean value and the brackets give the SE for groups of 8-10 mice. bearing animals eating diets of either calcium content. Thus, the hypercalcemia induced by the $\mathrm{HSDM}_{1}$ tumor does not depend on a ready source of dietary calcium, and the fall in plasma concentrations of calcium and $\mathrm{PGE}_{2}-\mathrm{M}$ in mice eating the menhaden oil diet cannot be explained by changes in calcium absorption from the gut.

\section{Discussion}

From the findings presented in this report we conclude, in mice of the Swiss albino strain bearing the PG-producing $\mathrm{HSDM}_{1}$ fibrosarcoma, that consumption of a diet enriched in EPA reduces the production of $\mathrm{PGE}_{2}, \mathrm{PGF}_{2 \alpha}$, and $\mathrm{PGI}_{2}$ without altering substantially the production of lipoxygenase products of arachidonic acid metabolism. The validity of this conclusion depends on the serologic specificity of the antisera used in the various radioimmunoassays employed. Because $\mathrm{PGE}_{3}$ reacts $\sim 20 \%$ with the anti-PGE ${ }_{2}$ used in these experiments, the decreases in levels of $\mathrm{PGE}_{2}$ in tumor tissue in mice fed the menhaden oil diet (Fig. 2) are minimal estimates of the decreased production of $\mathrm{PGE}_{2}$ itself. With respect to the $\mathrm{PGF}_{2 \alpha}$, 6-keto-PGF $\mathrm{F}_{1 \alpha}$, and $\mathrm{PGE}_{2}-\mathrm{M}$ analyses, the reactivities of the corresponding pentaenoic acid metabolites with our antisera are not known; thus, if substantial amounts of the respective trienoic derivatives were formed, the magnitude of the decreases we measured would be underestimated.

Decreased production of $\mathrm{PGI}_{2}$ has been observed when human endothelial cell cultures were enriched with EPA (12) and in a variety of other cell types as well (13). Similar findings 
were reported for rat aorta or smooth muscle cells $(30,31)$. However, other investigators have found that EPA did not decrease conversion of arachidonic acid to $\mathrm{PGI}_{2}(18,32,33)$. EPA may inhibit PG production by several mechanisms including displacement of arachidonic acid from tissue phospholipids and by inhibition of cyclooxygenase activity $(20,21)$. We measured modest decreases in the arachidonic acid content of liver and tumor tissue from mice fed the menhaden oil diet in comparison with the two control diets (Table II). This decrease was not due to either arachidonic acid deficiency or deficiency of the essential fatty acid 18:2 in the menhaden oil diet (Table I). Thus, in our experiments, only a portion of the decrease in the formation of cyclooxygenase products may be due to decreased arachidonic acid content of precursor phospholipid pools. In this context, it is noteworthy that a lack of decrease in $\mathrm{PGI}_{2}$ production in humans fed diets high in EPA may have been due to the lack of decrease of plasma (and possibly tissue) arachidonic acid pools (18). In this latter study (18), an increase in $\mathrm{PGI}_{2}$ production was found when measured as 2,3-dinor-6-keto-PGF ${ }_{1 \alpha}$ in the urine of three human subjects who were fed a mackerel diet. There are too many variables between our experiments and those of Fischer and Weber (18) to speculate on the cause of the contradictory findings.

In our experiments, levels of the lipoxygenase products, i12-HETE and iSRS, were not altered by the tumor or by the menhaden oil diet, which suggests that the serologic specificities of the 12-HETE and SRS antisera are not absolute with respect to pentaene and tetraene products. If they were, we would have expected a decrease in i12-HETE and iSRS levels, which we did not observe. It is possible that some decrease in tetraenoic HETEs and leukotrienes has occurred on the basis of decreased arachidonic acid availability, and that pentaenoic HETEs and leukotrienes are produced from the available EPA in tissues. Thus, the apparent lack of change in immunoreactive lypoxygenase products could be accounted for by substitution of products derived from eicosapentaenoic acid for analogous products derived from arachidonic acid (34). Previous reports have demonstrated that leukotrienes are readily synthesized from EPA, whereas cyclooxygenase products are less readily formed from EPA than arachidonic acid $(14,20)$. However, the possibility that the effects of dietary EPA on cyclooxygenase and lipoxygenase metabolites of arachidonic acid metabolism may vary substantially both among species and even between cells or tissues of the same animal must be considered.

We have previously reported a variety of kinds of evidence that have led us to postulate that $\mathrm{PGE}_{2}$ overproduction by the tumor is responsible for the elevation of plasma calcium concentration measured in mice bearing the $\mathrm{HSDM}_{1}$ fibrosarcoma (1-6). The results presented in this report are consistent with that conclusion. In tumor-bearing mice fed the menhaden oil diet there was a decrease in plasma $\mathrm{PGE}_{2}-\mathrm{M}$ (an indirect measure of $\mathrm{PGE}_{2}$ production), but to levels still significantly above those observed in control mice (Fig. 1). In parallel, the elevated plasma calcium concentrations in tumor-bearing mice were decreased significantly by feeding the menhaden oil diet, but again to levels still above those observed in nontumor- bearing animals (Fig. 1). We recognize that the magnitude of the decrease in plasma $P_{G E}-M$ is greater than that of calcium (Table II), but there is no a priori reason to postulate a direct linear relationship between these two parameters. On the other hand, it is possible that the greater incremental decrease in plasma $\mathrm{PGE}_{2}-\mathrm{M}$ than calcium could be explained by the following two events. First, EPA could be converted to $\mathrm{PGE}_{3}$, which does have some bone resorption stimulating activity (Tashjian, A. H., Jr., unpublished data). And second, the $\mathrm{PGE}_{3}$ formed was metabolized to $\mathrm{PGE}_{3}-\mathrm{M}$, which was not detected by our serologic assay for $\mathrm{PGE}_{2}-\mathrm{M}$. It is of interest to note that in the fifth experiment shown in Fig. 1 (the bars farthest to the right in each group), there was little or no decrease in plasma calcium in mice fed the fish diet, in comparison with those fed the regular or beef diets. In this experiment, the incorporation of EPA into tumor lipids was only $33 \%$ of that observed in the two other experiments analyzed (pooled data are presented in Table II). The results shown in Fig. 3 demonstrate that the hypercalcemia which occurs in tumorbearing mice is independent of dietary calcium content. Therefore, the effect the EPA-enriched diet on plasma calcium in mice bearing the $\mathrm{HSDM}_{1}$ tumor is not mediated by decreased absorption of calcium from the gastrointestinal tract. Thus, the findings reported in rabbits bearing the PG-producing $\mathrm{VX}_{2}$ carcinoma (29) do not apply to the $\mathrm{HSDM}_{1}$ fibrosarcoma. Finally, the observations that the menhaden oil led to a decrease in plasma calcium concentration without altering plasma or tissue concentrations of i12-HETE or iSRS argues against a role for these lipoxygenase products in the hypercalcemia induced by the $\mathrm{HSDM}_{1}$ tumor. In addition, there are no data available which demonstrate significant bone resorptionstimulating activity of HETEs or leukotrienes.

We conclude from analysis of body weights and tumor weights that effects of the menhaden oil diet on arachidonic acid metabolism and plasma calcium concentrations are not explained by a substantial inhibition of tumor growth in animals eating the fish oil diet. On the other hand, there was a consistent tendency for such animals to have smaller tumors without histologic evidence of changes in tumor cell morphology or inflammatory cell infiltration. These observations warrant further study to determine whether modifications of the experimental protocol might accentuate an effect on tumor mass. A similar small decrease in tumor size was seen in our earlier experiments in mice given indomethacin (4). Presumably these actions of indomethacin and EPA are not merely to inhibit PG production in the tumor cells because, at least in culture, the growth rate of $\mathrm{HSDM}_{1}$ cells is not appreciably slowed by concentrations of indomethacin that inhibit essentially completely the production of $\mathrm{PGE}_{2}$.

\section{Acknowledgments}

We thank Mr. Anthony Bimbo of the Zapata Haynie Company for generous gifts of menhaden oil, Keyes Lindsay and Dr. Roger Jeanloz for the gas-liquid chromatography analyses, Carl Boland for help with the statistical analysis, and Gregory Makoul for technical assistance.

This research was supported in part by research grants from the 
National Institutes of Health (AM 10206, ES 00002, AM 19427, AM 07258, GM 27256, and CA 17309).

\section{References}

1. Tashjian, A. H., Jr., E. F. Voelkel, L. Levine, and P. Goldhaber. 1972. Evidence that the bone resorption-stimulating factor produced by mouse fibrosarcoma cells is prostaglandin $\mathrm{E}_{2}$ : a new model for the hypercalcemia of cancer. J. Exp. Med. 136:1329-1343.

2. Tashjian, A. H., Jr., E. F. Voelkel, P. Goldhaber, and L. Levine. 1974. Prostaglandins, calcium metabolism and cancer. Fed. Proc. 33:81-86.

3. Tashjian, A. H., Jr., E. F. Voelkel, and L. Levine. 1982. Prostaglandins, tumor cells and bone metabolism. In Prostaglandins and Cancer. T. J. Powles, R. S. Bockman, K. U. Honn, and P. Ramwell, editors. A. R. Liss, Inc., New York. 513-523.

4. Tashjian, A. H., Jr., E. F. Voelkel, P. Goldhaber, and L. Levine. 1973. Successful treatment of hypercalcemia by indomethacin in mice bearing a prostaglandin-producing fibrosarcoma. Prostaglandins. 3:515524.

5. Tashjian, A. H., Jr., E. F. Voelkel, J. McDonough, and L. Levine. 1975. Hydrocortisone inhibits prostaglandin production by mouse fibrosarcoma cells. Nature (Lond.). 258:739-741.

6. Tashjian, A. H., Jr., E. F. Voelkel, and L. Levine. 1977. Effects of hydrocortisone on the hypercalcemia and plasma levels of 13,14dihydro-15-keto-prostaglandin $\mathrm{E}_{2}$ in mice bearing the $\mathrm{HSDM}_{1}$ fibrosarcoma. Biochem. Biophys. Res. Commun. 74:199-207.

7. Levine, L., P. M. Hinkle, E. F. Voelkel, and A. H. Tashjian, Jr. 1972. Prostaglandin production by mouse fibrosarcoma cells in culture: inhibition by indomethacin and aspirin. Biochem. Biophys. Res. Commun. 47:888-896.

8. Tashjian, A. H., Jr., J. E. Tice, and K. Sides. 1977. Biological activities of prostaglandin analogs and metabolites on bone in organ cultures. Nature (Lond.). 266:645-647.

9. Tashjian, A. H., Jr., and L. Levine. 1978. Epidermal growth factor stimulates prostaglandin production and bone resorption in cultured mouse calvaria. Biochem. Biophys. Res. Commun. 85:966975.

10. Schelling, S. H., H. J. Wolfe, and A. H. Tashjian, Jr. 1980. Role of the osteoclast in prostaglandin $\mathrm{E}_{2}$-stimulated bone resorption: a correlative morphometric and biochemical analysis. Lab. Invest. 42:290-295.

11. Voelkel, E. F., A. H. Tashjian, Jr., and L. Levine. 1980. Cyclooxygenase products of arachidonic acid metabolism by mouse bone in organ culture. Biochim. Biophys. Acta. 620:418-428.

12. Spector, A. A., T. L. Kaduce, P. H. Figard, K. C. Norton, J. C. Hoak, and R. L. Czervionke. 1983. Eicosapentaenoic acid and prostacyclin production by cultured human endothelial cells. J. Lipid Res. 24:1595-1604.

13. Levine, L., and N. Worth. 1984. Eicosapentaenoic acid: its effects on arachidonic acid metabolism by cells in culture. J. Allergy Clin. Immunol. In press.

14. Murphy, R. C., W. C. Pickett, B. R. Culp, and W. E. M. Lands. 1981. Tetraene and pentaene leukotrienes: selective production from murine mastocytoma cells after dietary manipulation. Prostaglandins. 22:613-622.

15. Lockette, W. E., R. C. Webb, B. R. Culp, and B. Pitt. 1982. Vascular reactivity and high dietary eicosapentaenoic acid. Prostaglandins. 24:631-639.

16. Scoini, A., C. Galli, C. Colombo, and E. Tremoli. 1983. Fish oil administration as a supplement to a corn oil containing diet affects arterial prostacyclin production more than platelet thromboxane formation in the rat. Prostaglandins. 25:693-710.
17. Anonymous. 1983. Eskimo diets and diseases. Lancet. I:11391141.

18. Fischer, S., and P. C. Weber. 1984. Prostaglandin $I_{3}$ is formed in vivo in man after dietary eicosapentaenoic acid. Nature (Lond.). 307:165-168.

19. Dyerberg, J., and H. O. Bang. 1979. Haemostatic function and platelet polyunsaturated fatty acids in Eskimos. Lancet. II:433-435.

20. Culp, B. R., B. G. Titus, and W. E. M. Lands. 1979. Inhibition of prostaglandin biosynthesis by eicosapentaenoic acid. Prostagland. Med. 3:269-278.

21. Lands, W. E. M., and M. J. Byrnes. 1981. The influence of ambient peroxides on the conversion of 5,8,11,14,17-eicosapentaenoic acid to prostaglandins. Prog. Lipid Res. 20:287-290.

22. Kenny, A. D., and P. L. Munson. 1959. A method for the biological assay of phosphaturic activity in parathyroid extracts. Endocrinology. 64:513-521.

23. Entenman, C. 1957. General procedures for separating lipid components of tissue. Methods Enzymol. 3:299-317.

24. Gaudet, R. T., I. Alam, and L. Levine. 1980. Accumulation of cyclooxygenase products of arachidonic acid metabolism in gerbil brain during reperfusion after bilateral common carotid artery occlusion. J. Neurochem. 35:653-658.

25. Axelrod, L., and L. Levine. 1982. Plasma prostaglandin levels in rats with diabetes mellitus and diabetic ketoacidosis. Diabetes. 31:994-1001.

26. Levine, L., and I. Alam. 1979. Arachidonic acid metabolism by cells in culture: analyses of culture fluids for cyclooxygenase products by radioimmunoassay before and after separation by highpressure liquid chromatography. Prostagland. Med. 3:295-304.

27. Rigas, A., R. A. Lewis, K. F. Austen, E. J. Corey, and L. Levine. 1983. Identification and quantitation of arachidonic acid metabolic products in rabbit, rat and human saliva. Arch. Oral Biol. 28:1031-1035.

28. Levine, L., R. A. Morgan, R. A. Lewis, K. F. Austen, D. A. Clark, A. Marfat, and E. J. Corey. 1981. Radioimmunoassay of the leukotrienes of slow reacting substance of anaphylaxis. Proc. Natl. Acad. Sci. USA. 78:7692-7696.

29. Doppelt, S. H., D. M. Slovik, R. M. Neer, J. Nolan, R. M. Zusman, and J. T. Potts, Jr. 1982. Gut-mediated hypercalcemia in rabbits bearing $\mathrm{VX}_{2}$ carcinoma: new mechanism for tumor-induced hypercalcemia. Proc. Natl. Acad. Sci. USA. 79:640-644.

30. Hornstra, G., E. Christ-Hazelhof, E. Haddeman, F. tenHoor, and D. H. Nugteren. 1981. Fish oil feeding lowers thromboxane- and prostacyclin-production by rat platelets and aorta and does not result in the formation of prostaglandin $I_{3}$. Prostaglandins. 21:727-738.

31. Morita, I., Y. Saito, W. C. Chang, and S. Murota. 1983. Effects of purified eicosapentaenoic acid on arachidonic acid metabolism in cultured murine aortic smooth muscle cells, vessel walls and platelets. Lipids. 18:42-49.

32. Dyerberg, J., and K. A. Jorgenson. 1980. The effect of arachidonic and eicosapentaenoic acid on the synthesis of prostacyclin-like material in human umbilical vasculature. Artery. 8:12-17.

33. Hamazaki, T., A. A. Hirai, T. Terano, J. Sajiki, S. Kondo, T. Fujita, Y. Tamura, and A. Kumagai. 1982. Effects of orally administered ethyl ester of eicosapentaenoic acid (EPA; 20:5 $\omega$-3) on PGI $_{2}$-like substance production by rat aorta. Prostaglandins. 23:557-567.

34. Leitch, A. G., T. H. Lee, E. W. Ringel, J. D. Prickett, D. R. Robinson, S. G. Pyne, E. J. Corey, J. M. Drazen, K. F. Austen, and R. A. Lewis. 1984. Immunologically induced generation of tetraene and pentaene leukotrienes in the peritoneal cavities of menhaden-fed rats. J. Immunol. 132:2559-2565. 